\title{
... Abyście się wzmacniali i przedłużali życie na ziemi. Eschatologia doskonałości, rygory Nidda i skandal higieny rasowej w okresie 1850-1945
}

\author{
Ewa Nowak \\ (Uniwersytet im. Adama Mickiewicza w Poznaniu, ewanowak@amu.edu.pl)
}

\section{Prawa życia w świetle nieporozumień}

Gdy Slavoj Žižek (2004, s. 501) pisał o "traumatyzujących, heteronomicznych i kontyngentnych" (Žižek 2004, s. 501) prawach żydowskich, sprzecznych z "organiczną samowiedzą i samourzeczywistnieniem" człowieka, najpewniej nie zdawał sobie sprawy z tego, że w judaizmie eschatologia splata się integralnie z witalizmem. Znaczna część halachy, której w Talmudzie odpowiada Traktat Nidda, odnosi się tutaj do żywotności, zdrowia (także reprodukcyjnego), profilaktyki, higieny i dietetyki, wreszcie długowieczności. Promuje ona wzrost jakości życia jako integralnej całości, która obejmuje też jego kondycję biologiczną. Ludzkie życie toczy się także na poziomie wegetatywnym i, jako takie, współtworzy bioeschatologiczną tożsamość człowieka, mimo, że natura sama przez się nie uosabia jeszcze wartości najwyższej eschatologicznej (świętości). Tożsamość ta posiada trzy wymiary: indywidualny, międzypokoleniowy i wspólnotowy. Trwanie i budowanie własnej tożsamości przez jednostkę i wspólnotę wiąże się najściślej z przywilejem wybraństwa. W imię tej mesjanistycznej samowiedzy od najdawniejszych czasów rygorystyczne przestrzegano praw, w tym kontrowersyjnej Niddy (Hogeterp 2008), której wykładnię aktualizowano zgodnie z rozwojem ludzkiej wiedzy (Popović 2005). Aby powiązać mesjanizm i etyczny rygoryzm z nauką, do formacji rabinicznej bardzo wcześnie włączano regularne studia naukowe, medyczne, biologiczne itd. Dzisiejszy judaizm, obejmujący liczne formacje konserwatywne i liberalne ale także ultraortodoksyjne sekty chasydzkie - nie będzie tutaj omawiany, albowiem nie do niego odnosił się spreparowany w połowie XIX w. mit i kontrmit "rasy", która jakoby od tysiącleci stosowała eugeniczne 'techniki siebie', pragnąc zdominować rodzaj ludzki.

Około połowy XIX w. wEuropie (a później także w Stanach Zjednoczonych Ameryki) scholastyczna antropologia ze swoim prymatem

1 Artykuł powstał w ramach grantu NCN Opus 9 nr 2015/17/B/HS1/02381 pt. „Ewolucja jaźni: przyczynek do rewizji posthumanizmu”. Autorka składa podziękowania Narodowemu Centrum Nauki za wsparcie prowadzonych przez nią badań. 
ducha nad ciałem ustępować poczęła bardziej naturalistycznej wizji człowieka w miarę rozwoju nauk biologicznych, medycznych i eksperymentalnych, zwłaszcza tak rozległych doktryn, jak teoria ewolucji, teoria dziedziczności, bakteriologia i epidemiologia, serologia itd. Wiedzę o funkcjonowaniu i potencjonowaniu żywego organizmu szybko przekuwano na zalecenia profilaktyczne, higieniczne, prozdrowotne, i dietetyczne, promujące długowieczność i przekazywanie życia w jak najlepszej kondycji.

Jednocześnie powszechna obecność oświeconej diaspory, która za sprawą asymilacji porzucała getta i angażowała się w działalność naukowobadawczą, sprzyjała wglądowi w żydowskie reguły życia. Europejskim naukowcom wydały się one uderzająco racjonalne i celowe, do tego stopnia, że dostrzegano $\mathrm{w}$ nich zgoła antycypację wiedzy i praktyki, jaką europejskie towarzystwa higieniczne dopiero definiowały i instytucjonalizowały. W umysłach zaskakująco wielu nieżydowskich naukowców zaświtało oto podejrzenie, że owe rytualne i skrzętnie skrywane przed światem zabiegi, praktyki i techniki służą wzmacnianiu tożsamości "ludu Izraela" w rozumieniu rasy semickiej w imię wspomnianej już dominacji. Interesowano się zwłaszcza zaleceniami dotyczącymi zdrowia reprodukcyjnego, dzietności żydowskich par i zdrowotności ich potomstwa. W świetle statusu wybraństwa, który w myśl "mitologii hebraistycznej" (Derrida 1985, s. 297) nie przysługuje żadnemu innemu ludowi, okoliczności te wzbudzały wśród Europejczyków niepokój.

Korzenie nowożytnej teorii ras sięgają pionierskich taksonomii stworzonych przez Berniera (ur. 1620), Buffona (ur. 1707) i współczesnego mu Karla Linneusza. Dzieło Systema naturae per regna tria naturae. Secundum: classes, ordines, genera, species cum characteribus, differentiis, sinonimis, locis wyróżnia cztery rasy homo sapiens, odwołując się do kryteriów kosmograficznych i morfologicznych, w tym przede wszystkim do odcienia ludzkiej skóry: Europaeus albus, Americanus rubescus, Asiaticus luridus i Afer niger. Oddzielny katalog ras przedstawił Johann Friedrich Blumenbach (ur. 1752) w De generis humani varietate nativa (1775). Obejmował on pięć ras, wyodrębnionych na podstawie analogicznych kryteriów: kaukaską, mongolską, etiopską, malajską i amerykańską (Buffon i inni wymieniali ich jeszcze więcej). U żadnego z tych badaczy nie pojawia się rasa "semicka", które to określenie wiąże się etymologicznie z imieniem biblijnego Sema, najstarszego z synów Noego. Słowo "semicki" pojawia się w użyciu ok. 1770 r. za sprawą getyńskiej szkoły historycznej. W owym czasie Żydów zaliczano do ludów kaukaskich lub Ariów; wszelako, od osiadłych Ariów miała ich różnić nomadyczność, dowodził w 1887 r. - w historycznym apogeum mitu rasy semickiej - Adolf Wahrmund (Das Gesetz des Nomadenthums und die heutige Judenherrschaft).

Pionierzy biologicznej teorii ras nie podważali jedności rodzaju ludzkiego; uczynił to dopiero Joseph-Arthur de Gobineau (1816-1882)22. Przed

2 Obraz jedności, a ściślej: pretendujący do uniwersalności, scholastyczny obraz białego, cywilizowanego mieszkańca chrześcijańskiej Europy ucierpiał kilka stuleci wcześniej, za sprawą odkrycia ludów pierwotnych (do niedawna pogardliwie zwanych "dzikimi"). Tylko nieliczni, tacy, jak Michel de Montaigne, identyfikowali się z nowymi 
nim zaistnienie jednej, ogólnoludzkiej cywilizacji uzależniano od tego, czy - jak wyraził to onegdaj Immanuel Kant (Bestimmung des Begriffs einer Menschenrasse, 1785) - "zarodki" i "zadatki" (Keime w terminologii Blumenbacha) człowieczeństwa, od techniczno-pragmatycznych po moralne, rozwiną się w jednakim stopniu u "rozmaitych" ras. Ówczesne antropologie pod pojęciem "rozmaitości" rozumiały zróżnicowane tempo rozwoju bądź realizacji pełnego potencjału ludzkiego ${ }^{3}$. Świadomość ludzka zarówno w tamtych czasach, jak i dziś jeszcze objawia tendencję do tego, by z (przesłanki) rozmaitości czy pluralizmu wnosić o nierówności, a dalej - segregować rozmaite elementy jako mniej lub bardziej wartościowe.

Afirmatywną ocenę "rozmaitości" znajdziemy u Herdera i Montaigne'a, $\mathrm{z}$ kolei znacznie mniej afirmatywną ( $\mathrm{z}$ tendencją do białego suprematyzmu) - $\mathrm{u}$ Hume'a i Kanta (Kleingeld 2007). Co ciekawe, pomimo apoteozy powszechnego rozumu, uniwersalizmu, kosmopolityzmu, etc. Oświecenie nie najlepiej radziło sobie z kolonialną teorią ras. Kilkadziesiąt lat później Charlesa Darwina zainteresują nie tylko naturalistyczne kryteria "dywergencji" ras, ale i "częściowo" kryteria natury poznawczej. To właśnie jego dzieło pt. $O$ pochodzeniu człowieka (1871) uświadamia istnienie idiomu rasy semickiej. Darwin zwraca w nim uwagę na "znikome różnice pomiędzy Europejczykami i Żydami, należącymi do pnia semickiego" (tamże, s. 214). W międzyczasie Gobineau (ur. 1816) i Galton (ur. 1822) zadbają o to, by teoria ras przekształciła się w narzędzie taksonomii typów ludzkich, obok kryteriach naturalistycznych wykorzystującej także kryteria mentalistyczne, esencjalistyczne, pragmatyczne, techniczne, wreszcie moralne.

Owo kolejne stulecie niosło ze sobą coraz mniej naukowe, a coraz bardziej zmitologizowane i upolitycznione wykładnie pojęcia 'rasa', razem z fobią na tle czystości rasy, krwi (w drugiej dekadzie XX w. grup krwi), nasienia, genów etc. (Torres 2006; Spörri 2013). Wykładnie te tworzyły grunt pod politykę higieny rasowej i eugeniki populacyjnej. Wówczas też zaczęto się baczni przyglądać tradycyjnym praktykom higienicznym i rytualnym judaizmu, aspirującego jakoby substancjalnego wzmacniania rasy semickiej celem

bliźnimi ludzkimi, tworząc z kolei mit bon sauvage. Gobineau z kolei, tworząc tzw. rasizm biologiczny (rasistowski biologizm) zapoczątkował dwa jego nurty: tzw. suprematyzm rasowy oraz rasizm odwołujący się do czystości (zwykle: czystości krwi). Jego koncepcje należały do najgroźniejszych, tzn. poszukiwano dla nich legitymizacji naukowo-empirycznej by uczynić je samooczywistymi (Gobineau, Essai sur l'inégalité des races humaines, 1853-55).

3 Z kolei pojęciem "zarodków" i "zadatków" posługiwał się nurt preformacjonistyczny, powiązany $\mathrm{z}$ natywizmem. Przedstawiciele tych nurtów postrzegali organizm jako indywiduum odizolowane od środowiska życia, które swój wzrost i rozwój zawdzięcza immanentnym, wrodzonym "siłom" lub "zadatkom". Stanowiskiem przeciwstawnym, opisanym m.in. przez Darwina i Voegelina, jest epigenetyzm, krzyżujący plany zwolennikom dziedziczenia rodowo-linearnego. Epigenetyzm był dobrze znany także w tradycji judaistycznej. Epigenetyzm nie jest więc nowym odkryciem, podobnie, jak koncepcja organizmu, który "staje się sobą procesualnie, nie bądąc bytem statycznym" (does not signify a static entity, individuality is the moment of a process of becoming) (Heilke 1990, s. 73; por. Shildrick \& Mykitiuk 2006). 
kosmopolitycznej ekspansji. Dedukowano tę aspirację m.in. na podstawie diasporycznego sposobu życia i zakazu zawierania małżeństw mieszanych, interpretowanych jako oznaki dążności do owej rasowo-populacyjnej hegemonii. W odpowiedzi na mit rasy semickiej rodził się z wolna kontrmit ras zagrożonych, które wymagają "wzmocnienia".

Przez niemal stulecie, do 1945 r., ten podwójny mit legitymizowały rozmaite osobistości i instytucje świata nauki. Na przełomie stuleci przybrał on formy jawnej, zorganizowanej segregacji, dyskryminacji i eksterminacji na tle rasowo-eugenicznym, stosowane głównie wobec członków diaspory żydowskiej, a z nieco innych względów - również wobec mniej licznej diaspory romskiej. Do prześladowanych dołączały kolejno inne grupy, których znamiona genotypowe i fenotypowe definiowano politycznie (Heilke 1990). Faza rasismu eugeniczno-politycznego jest dość rzetelnie opracowana, ale ów podwójny mit wraz z towarzyszącym mu nadużyciem jest słabo znany. Warto go sobie przybliżyć z kilku powodów: jednym z nich jest nadal żywe dziedzictwo owego mitu, żywiącego się ludowymi i pseudonaukowymi przeświadczeniami o tym, że określona rasa bądź etnia dąży do uzyskania przewagi nad innymi, również w znaczeniu mitologizowanym jako metafizyczno-egzystencjalistyczny spisek (pokazał to Trawny na przykładzie "czarnych brulionów" Martina Heideggera).

Podłoże tego mitu - wywodzi Eric Voegelin, którego ustalenia wysoko ceniła Hannah Arendt - jest polityczne. Odwołuje się on bowiem już nie do hierarchii międzygatunkowej (jak u Buffona, Linneusza i Darwina), lecz do wewnątrzgatunkowej hierarchii grup ludzkich ze względu na odrębne pochodzenie i znamiona rasowe. Ignorowanie eschatologicznego wymiaru żydowskiej ideałów wybraństwa, kontynuacji i doskonalenia integralnego (Peterson 1982; Nowak 2014) stanowiło i nierzadko nadal stanowi pożywkę dla rezonowania na temat 'przewagi', którą należy 'demaskować' w celu zachowania przeciwwagi tej grupy, która definiuje swoją tożsamość w kategoriach rasy, rodu i narodu (a niekiedy w jeszcze bardziej archaicznych kategoriach "czystości krwi"4).

Mit ten powielają dezinterpretacje dokonywane $\mathrm{w}$ odniesieniu do określonych filozofemów. Na takie dezinterpretacje podatne jest zwłaszcza pisarstwo Nietzschego, w oczach którego żydowskość koncentrowała w sobie "wolę mocy", rozproszoną jakoby w bardziej egalitarnym od judaizmu chrześcijaństwie (Simon 2000).

Skoro mowa o micie, warto przypomnieć za Voegelinem (1901-1985), że mit jest konstrukcją psychologiczną, w dużej mierze opartą na przekonaniach (ideologicznych bądź spekulatywnych), a częściowo jedynie - na ewidencji empirycznej. Psychologizm leżący u podstaw mitu rasy polega na tym, że z własności obserwowalnych (morfologicznych, behawioralnopragmatycznych, etc.) wnioskuje się o właściwościach psychicznych i charakterologicznych człowieka. Podobnie czyniły arachaiczna "fizjognomika" i

4 Istnieją mity i kontrmity znaczenie starsze, $\mathrm{w}$ najjaskrawszym stopniu sprzeczne zwłaszcza z zakazem kontaktu z krwią jako zjawiskiem ambiwalentnym ("bo we krwi jest życie") (le Mosse 2000). 
"morfoskopia" (Popović 2005), a później - frenologia, antropometria, tj. prekursorki współczesnej biometrii. Gdy miesza się parametry biometryczne z psychometrycznymi, intrepretując tę mieszaninę w kategoriach politycznych, pociąga to za sobą szereg zagrożeń społecznych. W tym kontekście warto przypomnieć dwa typy teorii ras, wskazane przez Erica Voegelina: "typ pierwszy obejmuje spekulatywne rozwiązania problemów związanych $\mathrm{z}$ ontyczną naturą człowieka i jego biologiczną przynależnością, rozszerzając je na obszar psychiki. Typ drugi odnosi te spekulacje do relacji pomiędzy biologicznie zróżnicowanymi grupami w perspektywie historycznej (...) i politycznej" (Heilke 1990, s. 106). Aby przybliżyć rasowość z nowej, jak powiada Heilke, "genealogiczej" perspektywy w Die Rassenidee in der Geistesgeschichte, Voegelin polemizował z Linneuszem, który definiował różnice między rasami w kategoriach czysto biologicznych (naturalistycznych).

Socjologiczną koncepcję rasizmu w odwołaniu do kategorii naturalistycznych u schyłku XX w. zaproponował Tzvetan Todorow: "słowo 'rasizm' w swoim znaczeniu potocznym oznacza dwie różne rzeczy. Z jednej strony chodzi o zachowania manifestujące nienawiść lub pogardę dla jednostek o wyraźnie zdefiniowanych cechach zewnętrznych, odmiennych od naszych; z drugiej strony, chodzi o ideologię i doktrynę ras ludzkich. Te dwie kwestie nie muszą być ze sobą powiązane (...) Rasy porównuje się do gatunków zwierząt, postulując dystans między dwoma rasami ludzkimi, analogiczny do tego, jaki występuje między końmi i osłami. Nie chroni on wprawdzie przed [transgatunkową] reprodukcją, ale wystarcza do stworzenia oczywistej dla wszystkich granicy. Rasiści (...) są przeciwni mieszaniu ras", wyjaśnia Todorov (2000, s. 64-65). Wedle Todorova, podobnie jak wedle Voegelina, do ideologii rasowej należy przekonanie o "ciągłości pomiędzy fizjonomią (physical type) a charakterem. Jednak rasa nie składa się tak po prostu $\mathrm{z}$ podobnie wyglądających indywiduów. Rasa jest także rodzajem segmentu kulturowego. Jedna rasa może posiadac więcej kultur. Solidarność między rasą i kulturą sprawia, że rasy mogą prowadzić ze sobą wojny" (tamże, s. 65).

W świetle antagonizmu ras okazuje się, że to nie rytualne rygory Nidda, immanentnie służące życiu, stanowiły dla Żydów źródło opresji (jak uważa Žižek). Źródłem opresji stały się dopiero rygory rasistowskiej polityki, wymierzone $\mathrm{w}$ rasę semicką jako jedną z tych grup ludzkich, których "naturę" przeciwstawiono "naturze" innych, $\mathrm{z}$ całym mitologiczno-historycznym suplementem, jaki do "natury" owych grup dołączyły ideologie.

Należy teraz przybliżyć witalistyczno-eschatologiczną istotę rytualnych zasad Nidda, regulujących zarówno witalistycznie, jak i eschatologicznie rozumianą kondycję "ludu Izraela". Wyraża je 365 spośród ogółem 613 przykazań, "a liczba ta koresponduje z liczbą dni w roku. 248 nakazów odpowiada częściom ludzkiego ciała", tłumaczy Hammer (2010, s. 21). Koncentracja na cielesności współgra z eschatologią Majmonidesa (a także Akwinaty), wedle której integralny rozwój - nie zaś dusza sama albo paulińskie 'nowe ja' - pozwala człowiekowi osiągnąć świętość. W judaizmie życie podług określonych reguł oznacza zatem doskonalenie integralne (Coward 2008), 
którego cel przekracza indywidualistyczną teleologię praktyk aretaicznych, pielęgnowaną $\mathrm{w}$ tradycji grecko-scholastycznej. Niejakie analogie $\mathrm{z}$ aretaizmem można odkryć, porównując myśl Arystotelesa, Akwinaty i Majmonidesa: nie będę ich tutaj omawiać. Unikalny charakter integralnego doskonalenia w judaizmie obejmuje zarówno samozachowanie i witalizm pojedynczego organizmu, jak i międzypokoleniowe dziedziczenie żywotności, zdrowotności, reproduktywności i długowieczności (Washowsky 2009; Fonrobert 2000, 2007). Zakłada dbałość o życie jako całość, od dietetyki przez zdrowie reprodukcyjne po higienę umysłową: "przestrzegajcie tedy wszystkich przykazań, które wam przykazuję dzisiaj - abyście się wzmocnili i poszli...", powiada Księga Dewarim (XI, 8).

Niniejsze opracowanie przywołuje Niddę jedynie egzemplarycznie, nie brak tu bowiem opracowań szczegółowych (Nowak 2014). Chodzi jedynie o wskazanie witalistyczno-eschatologicznego punktu odniesienia dla praktyk doskonalenia integralnego, zwłaszcza w ortodoksyjnych formacjach judaizmu (jednak z pominięciem współczesnego chasydyzmu, uważanego za sektę). Z najpierwszym przykazaniem Nidda: "bądźcie płodni i rozmnażajcie się", mierzyli się już biblijni protoplaści Izraela: Sara i Abraham, Rywka i Izaak. Dla talmudystów skarga Racheli: "spraw, abym miała dzieci, bo inaczej przyjdzie mi umrzeć"; Bereszit XXX, 13) stała się przesłanką traktowania osób bezdzietnych w taki sposób, jakby zostały osierocone przez własne dzieci ${ }^{5}$ (por. Weitzman 2009, s. 207). Ten rygoryzm może nas zadziwiać podobnie, jak determinacja, z jaką Rachela i Lea szukały dla współmałżonków zastępczych matek dla swych pierworodnych. Biblijne protoplastki zainicjowały tym samym metodę poczęcia wspomaganego przez osoby trzecie (por. Edwards et al. 19931/2005)6. Ideał doskonalenia integralnego znajduje wyraz w życiu współczesnej diaspory i polityce zdrowotnej państwa Izrael. Reguły zdrowia reprodukcyjnego dyktuje Księga Szemot (XXII,26): "Nie będzie roniącej ani niepłodnej w kraju twoim". Inne, zdrowotne, dietetyczne i higieniczne reguły ${ }^{7}$ ) stanowią $\mathrm{w}$ judaizmie trwałe instytucje społeczne, pomyślane tak, by wspierać ludzi podczas "całej

\footnotetext{
5 W dosłownym rozumieniu: jak gdyby osieroconych przez własne dzieci; była to nie tyle forma ostracyzmu społecznego, ile aura żałoby, roztaczająca się wokół niespełnionych rodzicielek i rodzicieli. W judaizmie bezdzietność stanowi dostateczne uzasadnienie dla rozwodu i prokreacji wspomaganej klinicznie. Ortodoksyjnym małżeństwom Talmud zaleca rozwiązanie małżeństwa, jeśli po dziesięciu latach pożycia nadal pozostają bezdzietne (Yevamot 64a; por. Weitzman 2009, s. 208); uzasadnia takie działanie prawem halachicznym wyższego rzędu, nakładającym na małżonków obowiązek prokreacyjny.

6 W 1996 r. Izrael jako pierwsze państwo na świecie zalegalizował tę praktykę (The Surrogacy Arrangement Act, 1996; por. Landau, s. 136-137), wprowadzając przy okazji ustawodawstwo bioetyczne, umożliwiające donację komórek rozrodczych i zapłodnienie in vitro. W międzynarodowych statystykach Izrael zajmuje czołową pozycję pod względem liczby poczęć in vitro. Zakaz prawny obejmuje z kolei donację, import i zamrażanie embrionów. Regulacje te podporządkowane są zasadzie naczelnej, wedle której każdy człowiek ma prawo do posiadania potomstwa.

7 Łącznie z obchodzeniem świąt, które nie polega na bezczynności ani też celebracji ciała; jest to raczej celebracja życia w pół (mesjanistycznej) drogi.
} 
drogi, którą wskazał wam Wiekuisty (...) abyście żyli i dobrze się wam wiodło, i żebyście przedłużyli dni wasze na ziemi, którą posiądziecie" (Dewarim V, 30).

\section{Nauka jako matecznik mitu}

W połowie XIX w. pionierzy teorii dziedziczności i eugeniki poczęli wertować źródła halachiczne, uznawszy żydowski modus vivendi za prototyp wspomaganej ewolucji i zgoła świadomej polityki stworzenia „rasy” żydowskiej. W owym czasie Eric Blumenthal donosił, że „można przytoczyć niezliczone pasaże świadczące o tym, iż prawa religii są kluczowe dla praktykowania fizycznego i duchowego dobrostanu, żywości umysłu i tężyzny fizycznej wśród Izraelitów" (Blumenthal 1859, s. 340). Neofici 'odkrywali' prozdrowotne praktyki i rytuały, upatrując w nich kliniczne dowody na oddziaływanie (i zgoła ekwiwalent!) „koncepcji eugenicznych, tożsamych z zasadami zawartymi w Piśmie (Holy Writ). "Lud Izraela - dowodził w latach dwudziestych XX w. Thurman B. Rice, znany amerykański krzewiciel zdrowia publicznego - to jeden z najbardziej udanych i spektakularnych eksperymentów w całej rasowej kulturze ludzkości" (Rice 1929). Podobne idee rozpowszechniali Redcliffe Salaman, William Feldman czy Caleb Saleebi, upewniając współczesnych o tym, jakoby odsłonięto właśnie skrywane dotąd przed światem tajniki osobliwie „inteligentnej opieki prenatalnej i postanatalnej” (Feldman 1986, s. 107), kultywowanej celem wyhodowania domniemanej „rasy semickiej”. Tajniki te miały wyróżniać i uprzywilejowywać judaizm na tle innych religii. Badaczy intrygowało zwłaszcza "przyzwolenie na sterylizację kobiety, jeśli ta miałaby wydać na świat potomstwo obciążone chorobami somatycznymi lub psychicznymi" (Feldman 1986, s. 107).

W drugiej połowie XIX w. przedmiotem osobnej, biopolitycznej opresji stało się też obrzezanie mężczyzn. Zarzucano je m.in. w Niemczech gwoli lepszej asymilacji (Judd 2007; Levit 1874). Rezygnacja z najważniejszej anatomicznej oznaki żydowskiej tożsamości odniosła jednak skutek przeciwny do zamierzonego, wzbudzając podejrzenia o zacieranie i ukrywanie tożsamości po to, by podstępnie kolonizować inne grupy społeczne, a także instytucje. Fiasko asymilacji wymownie ujął Heinrich Heine, dla którego „Żyd nieobrzezany to ni pies, ni wydra" (neither flesh no fowl). Kontekst eschatologiczny objaśnia, że obrzezaniu poddał się protoplasta rodu, Abraham, by zjednać sobie witalistyczne błogosławieństwo Stwórcy dla męskiej linii rodu (Knust 2011, s. 202). Byłaby to modyfikacja ciała o wybitnym znaczeniu dla tożsamości rodu, przyrównana u Knust do modyfikacji typu germ-line. Praktykowane rówież w islamie i innych kulturach obrzezanie posiada bogatą symbolikę, której nie sposób tutaj omówić.

$\mathrm{W}$ jednej $\mathrm{z}$ licznych analogii, jakich doszukiwano się między ewolucjonizmem a kultywowaniem własnej kondycji przez Żydów (czy raczej domysłami na ten temat), XIX-wieczni badacze przyrównywali „ciąg historycznych doświadczeń związanych z segregacją, wykluczeniem, opresją, cierpieniem, przemocą i śmiercią" (Hart 2007, s. 107) wśród Żydów do 
Darwinowskiej „walki o byt”. Przyjmowali, że doświadczenia takie „można traktować jako integralny etap procesu selekcji naturalnej, prowadzącej do eliminacji słabszych z jednej strony, a z drugiej - do przetrwania silniejszych, bardziej witalnych Żydów" (Hart 2007, s. 107). Biologiczną adaptację i dostosowanie kojarzono też $\mathrm{z}$ asymilacją. Wypowiedzi te $\mathrm{w}$ sposób niemal kliniczny ilustrują wskazane przez Voegelina przejście od teorii ras typu I do teorii ras typu II. Zredukowaną do wyrwanych z kontekstu praw ewolucji "naturę ludzką" jednej grupy - w tym wypadku klasyfikowanej jako 'semicka' wyposażono w spekulatywny profil psychofizyczny, a następnie ulokowano w polityczno-historycznej relacji z jej społecznym otoczeniem. Z

Max Reichler, XIX-wieczny rabin, a zarazem medyk i biolog o wykształceniu zgodnym $\mathrm{z}$ duchem czasu, dostrzegał pełną ekwiwalencję pomiędzy uosabianą przez patriarchę Abrahama troską o czystość rodu a eugeniką. „Eugeniczne” znamiona nosił jakoby fakt, że Abraham poszukiwał odpowiedniej małżonki dla syna Izaaka. Małżeństwa z kobietami wywodzącymi się z odpowiedniego „szczepu” miały zapobiegać marnotrawstwu świętego nasienia, pilnie strzeżonego ze względu na tożsamość rodu (Hart 2007, s. 107110; por. Knust 2011, s. 146).

W determinacji, z jaką odwieczne żydowskie rytuały przekładano na awagardowowy język doktryny ewolucji, dziedziczności itd., przejawiało się marzenie o emancypacji, a także włączeniu medycyny rabinicznej w światowy nurt nauki (Feldman 1917). Jednak powszechne przypisywanie znamion eugenicznych rytuałom i praktykom żydowskim szybko przybrało charakter demaskatorski, perwersyjny, prowadzący do nowej fali suprematyzmu i antysemityzmu. Wyziera on explicite z wypowiedzi o "fetyszyzacji higieny" (Hart 2007, s. 109), tłumaczeniu ortodoksyjnego zakazu małżeństw mieszanych "świadomością i solidarnością rasową" (Hart 2007, s. 108), a doboru par rodzicielskich i nadopiekuńczego macierzyństwa - celowym wspomaganiem selekcji naturalnej przez religię:

żydowska matka to matka dzieci o przyrodzonej wyższości (of children innately superior), ponadprzeciętnych, bowiem są one owocem ostrej, trwającej przez stulecia selekcji i doboru par rodzicielskich. Jako taka, czyni ona dla swych dzieci nieporównanie więcej aniżeli inne matki czynią dla swoich i zaniedbuje opiekę nad nimi jedynie w skrajnym wypadku, gdy nie da się inaczej. Opieka macierzyńska przewyższa u niej pod każdym, najdrobniejszym względem opiekę sprawowaną przez jej nie-żydowskie siostry (is incomparably superior to that of her Gentile sister). Niebotyczne standardy macierzyństwa u rasy wybranej wydały plon, który możemy zaobserwować współcześnie ..." (Saleebi 1909, s. 317; por. Fonrobert 2007).

Gorliwi tropiciele żydowskiej eugeniki powoływali się przy tym na skuteczność higienicznych i dietetycznych rytuałów, potwierdzoną badaniami porównaczymi, jakie prowadzono wśród ludności krajów Europy na przełomie XIX i XX na fali odkryć bakteriologii, epidemiologii etc., z myślą o tym, by propagować higienę, profilaktykę i zdrowie publiczne. Ich wyniki rzeczywiście 
wskazywały, że populacja diaspory wykazuje "najwyżej rozwiniętą odporność na malarię, zwyrodnienia układu oddechowego, choroby skórne, choroby przewodu pokarmowego i przepuklinę. Zapada ona ponadto znacznie rzadziej na tuberkulozę aniżeli pozostała część populacji" (Glatter 1903, I)8.

Zdawałoby się, że postęp nauk medycznych i krzepnący w owym czasie resort zdrowia publicznego podważą nareszcie szkodliwy mit żydostwa zdegenerowanego, o „niezdrowej woni” (Gilman 1997, s. 93), wegetującego w gettach. Mit ten zweryfikował już „anty-antysemita” Nietzsche (Gilman 1997, s. 68). W jego pismach, zwłaszcza $Z$ genealogii moralności, Antychryst i Poza dobrem i złem, znaleźć można szereg niespójnych osądów, łącznie z apoteozą „rasowo najczystszej semickości” (die reinste Rasse), której potęga wzrastała przez długie tysiąclecia. W potędze tej Nietzsche dostrzegał „potencjał zdolny podtrzymać zagrożoną jedność kulturową Europy" (Brömsel 2011, s. 260). Gilles Deleuze dostrzegł w poglądach Nietzschego osobliwy konstrukt rasy jako integralnego typu ludzkiego $\mathrm{w}$ rozumieniu antropologii kulturowej. Kumulują się w nim siły twórcze, artystyczne i moralne. Jak z kolei podkreśla Brömsel i co staram się też uwidocznić w tym opracowaniu, „wyobrażenie, jakie o żydostwie miał Nietzsche, nieustannie oscylowało pomiędzy witalizmem i dekadencją, geniuszem i degeneracją. Przeciwieństwa te mogą się nawzajem łączyć, ale mogą też generować napięcie. Nietzsche nie jest ani filosemitą, ani antysemitą: raczej waha się między tymi dwoma skrajnościami" (Brömsel 2011, s. 261).

Badacze, propagatorzy zdrowia populacyjnego i aktywiści towarzystw higienicznych (Ramsden 2008) dokonali demistyfikacji i zarazem mistyfikacji rytuałów i praktyk żydowskich. Spreparowali nowy mit żydowskiego stylu życia, mającego jakoby za cel wzmacnianie potęgi rasy semickiej w warstwie biologicznej i politycznej. Wystarczyło raptem kilka dziesięcioleci, by usankcjonować mit instytucjonalnie, angażując $\mathrm{w}$ ten proces naukę, służbę zdrowia i prawodawstwo zainteresowane rozwiązaniem "kwestii żydowskiej" w drodze likwidacji "rasy semickiej". 0 tym, że pomysłodawcy tych rozwiązań manipulowali wiedzą o religii żydowskiej, przeinaczali odkrycia nauk o życiu, zafałszowywali awangardowe teksty kultury i legitymizowali nimi swe zbrodnicze idee polityczne, wymownie świadczy przekonanie Adolfa Hitlera o tym, że religia jest doktryną służącą wyłącznie zachowaniu rasy semickiej.

Zarysowując logikę i dokumentując w zarysie przebieg tego procesu, prowadzącego do nowej fali antysemityzmu nowej o niespotykanej dotychczas sile destrukcji ${ }^{9}$, warto zadać sobie następujące pytanie: czy w obliczu opisanych

8 O wysokiej świadomości profilaktyczno-epidemiologicznej Izraelitów świadczy obszerny pasaż w III Księdze Tory (Wajikra XXII), poświęcony trądowi.

${ }^{9}$ Która w omawianym okresie koncentrowała się na dwóch rasach/etniach trwających w diasporach. W XIX-wiecznych Niemczech społeczno-polityczne połóżenie diaspory żydowskiej uznawano za nieco korzystniejsze od położenia diaspory romskiej: „dziewiętnastowieczni Niemcy stykali się z dwoma mniejszościami etnicznymi w łonie swojego społeczeństwa, traktując ich członków - tj. Żydów i Romów - jako 'Innych' (two ethnic minority groups in their midst who were perceived as "Others"). Podczas, gdy mniejszość żydowska czynnie asymilowała język i kulturę niemiecką, podpisując się 
tutaj nadużyć wolno rozważać tradycję Nidda w świetle współczesnej fali eugeniki, już nie tyle populacyjnej, ile liberalnej? (Bardziński 2014).

Formacje ortodoksyjne, reformowane i liberalne w obrębie judaizmu niezmiennie czerpią z witalistycznego i perfekcjonistycznego przesłania reguł halachy i hagady. Równolegle, afirmatywne „tak dla życia” również ze strony ultraortodoksyjnego chasydyzmu (Lewis 2009, s. 251) wchodzi w konfrontację z najnowocześniejszymi osiągnięciami nauki i techniki. Owo „tak” wyraża również immanentną „rewitalizację” (Mendes-Flohr 1997, s. 236) żydowskiej wrażliwości, niezależnie od podtrzymanego jeszcze przez Martina Bubera, a wyraźnie też nietzscheańskiego przekonania o „pasywnie i zarazem negatywnie usposobionym duchu semickim” (Mendes-Flohr 1997, s. 236), którego „gwoli życia pełnego i twórczego (...) w rozumieniu afirmacji życia" (Mendes-Flohr 1997, s. 236-239) pobudzać musiała „heteronomiczna filozofia” (Zank 2012) ale chyba nie heteronomiczne prawa, o jakich pisał Žižek. Najwyraźniej więc judaizm posiada immanentne, niewyczerpane pokłady witalizmu, niezbędne do promowania „życia jako takiego” (Scholem 2007, s. 306) i podlegają one ochronie za sprawą dość rygorystycznych, a przecież potencjonujących życie zasad, nie dopuszczających do marnotrawstwa i degeneracji10 jego biologicznych podstaw. Nawet, jeśli współczesna, liberalna wykładnia tych rygorów jest stosunkowo przychylna technologiom biomedycznym, ich stosowanie nigdy nie miało nic wspólnego z biopolityką i eugeniką populacyjną, które dopuszczały się masowo przymusowych sterylizacji, neonatalnych eutanazji i innych zbrodniczych praktyk. W przeciwieństwie do pojęcia rasy w sensie antropologii politycznej, zbadanego przez Voegelina (1933a, b) i Heilkego (1990), na gruncie kultury żydowskiej pojęcie rasy - gdyby w ogóle zaistniało - nie zyskałoby konotacji upolityczniających preferowane atrybuty psychofizyczne, mające zapewnić hegemonię jednej rasy nad innymi. Żydowska diaspora ma strukturę swoistą, niezależną od struktur państwowopolitycznych. Historycznie rzecz biorąc, na terenie państw, w których występowała, tworzyła getta w sensie już to pozytywnym (z nadania monarchów i książąt, aby umożliwić diasporze wspólne i niezakłócone egzystowanie), już to negatywnym (jako enklawę życia dla jednostek, które powinny znać swoje miejsce). Z kolei judaizm w swych (nieczęstych) aspiracjach syjonistyczych, odróżniający dla przykładu "typ" sefardyjski od aszkenazyjskiego, nie jest zainteresowany budowaniem określonego "archetypu" (termin Voegelina) psychofizycznego, który uzasadniałby segregacji czy zgoła przynależność do "ludu Izraela". Wszelako, antropologia religii opisała archaiczną żydowską fizjognomikę, wedle której dokonywano niegdyś identyfikacji noworodków z uwagi na widoczne oznaki pochodzenia

całym sercem pod dziedzictwem oświecenia i progresem społecznym, a przy tym odnosząc znaczące sukcesy na wielu polach, mniejszość romska tego nie czyniła" (Reershemius 2009, s. 184).

${ }^{10}$ Gershom Scholem (2007, s. 306) pisał o potrzebie zapanowania (kawanna) nad siłami życia ,jako takiego”. „Życie każdego ze światów i każdej z jego sfer jest w ciągłym ruchu, w ciągłym rozwoju; dąży ono do znalezienia najwłaściwszej sobie formy, która wyzwoli je z chaotyczności 'życia jako takiego'". 
bożego (Popović 2005; Hogeterp 2008; Nowak 2017). W judaizmie kryteria przynależności rodowej i wspólnotowej nadal pozostają kryteriami natury biologiczno-mesjanistycznej: decyduje tu urodzenie przez żydowską matkę. Co do swej istoty, eschatologia zakłada dążność do ponadindywidualnej, historycznej "ciągłości i znaczenia" (Heilke 1990, s. 127), jakie powinna zapewnić sobie wspólnota wychodząc na spotkanie Mesjaszowi: w gotowości na nie tkwi przyczyna integralnej dbałości, opisanej m.in. przez Agambena.

Po Zagładzie historyczność i eschatologia były dyskutowane i kwestionowane wśród żydowskich intelektualistów. Z drugiej strony, spektakularnym wyrazem żydowskiego witalizmu stał się baby boom obserwowany wśród młodych kobiet, które przetrwały obóz koncentracyjny. 29\% z nich powiło w kilka miesięcy po wyzwoleniu (Furman \& Feierstein 2007, s. 42); w 1948 r. było to już 35,8\%. Odpowiednio, dzietność wśród kobiet bawarskich w tym samym czasie wynosiła zaledwie 7,35\%.

$\mathrm{Na}$ koniec powstaje pytanie, czy ludzka (w sensie gatunkowym) tożsamość - a przede wszystkim naturalnie uwarunkowana rozmaitość, której na fali Oświecenia wróżono homogenizację pojmowaną jako przejaw uniwersalizmu - są dzisiaj bezpieczne w obliczu innych, lecz niezmiennie biopolitycznych zagrożeń, procedur, ideologii: czy wypracowaliśmy standardy prawne i etyczne, a także antropologiczny obraz człowieka z jego wyjątkowym potencjałem, chroniące przed coraz bardziej zaawansowanymi technologiami, które można wykorzystać zarówno w celach identyfikacyjnych, jak i segregacyjnych bądź supremacyjnych, a nawet takich, jak (osobniczo nieodwracalna) zmiana ludzkiej tożsamości na postludzką?

\section{Literatura}

Bardziński, F. 2014. "Transhumanism and Evolution. Considerations on Darwin, Lamarck, and Transhumanism." Ethics in Progress, Vol. 2(5): 103-115.

Blumenbach, J. F. 1798. Über die natürlichen Verschiedenheiten im Menschengeschlechte: Leipzig.

Blumenthal, M. 1859. "The Sanitary and Dietetic Laws of the Hebrews." The New York Journal of Medicine (pp. 339-357). New York: H. Baillière.

Blyth, E. \& Landau, R. (eds.) 2004. Third Party Assisted Conception Across Cultures. Social, Legal, and Ethical Perspectives. London - New York: Jessica Kingsley Publishers Ltd.

Brömsel, S. 2011. “Judentum”. W H. Ottmann (Hrsg.) Nietzsche-Handbuch. Leben - Werk - Wirkung (s. 260-262). Stuttgart - Weimar: J. B. Metzler Verlag.

Cohen, H. 2004. Ethics of Maimonides. Trans. by A. Sh. Bruckstein, Foreword by R. Gibbs. London: The University of Wisconsin Press.

Cohen, A. 2016. "Harvard's Eugenics Era." Vol. 118, No. 4: 48-60.

Coward, H. 2008. The Perfectibility of Human Nature in Eastern and Western Thought. Albany: State University of NY Press.

Derrida, J. 1985. “Racism's Last Word.” Critical Inquiry, Vol. 12, No. 1: 290-299. 
Feldman, D. M. 1986. Health and Medicine in the Jewish Tradition. New York: Crossroad.

Feldman, W. 1917. The Jewish Child: Its History, Folklore, Biology, and Sociology. With an Introduction by Sir James Crichton Browne. London: Baillière.

Fonrobert, Ch. E. 2000. Menstrual Purity. Rabbinic and Christian Reconstructions of Biblical Gender. Stanford, CA: Stanford University Press.

Fonrobert, Ch. E. 2007. "Regulating the Human Body: Rabbinic Legal Discourse and the Making of Jewish Gender". W Ch. E. Fonrobert \& M. S. Jaffe (eds.) The Cambridge Companion to the Talmud and Rabbinic Literature (pp. 270-294). Cambridge - New York - Melbourne - Madrid - Cape Town Singapore - São Paulo: Cambridge University Press.

Furman, L. \& L. R. Feierstein. 2007. "The Paper Bridge. Jewish Responses to Destruction." European Judaism, Vol. 40(1): 38-55.

Gilman, S. E. 1993. "Heine, Nietzsche, and the Idea of the Jew." W J. Golomb (ed.) Nietzsche and Jewish Culture (pp. 76-100). New York: Routledge.

Glatter, E. 1903. "Über die Lebens-Chancen der Israeliten gegenüber der christlichen Confessionen." W H. Hoppe (Hg.) Krankheiten und Sterblichkeit bei Juden und Nichtjuden, 1. Berlin: Calvary.

Hammer, R. 2009. "Judaism As a System of Mitzvot." Conservative Judaism, Vol 61(3), Spring: 12-25.

Harrington, H. K. 2008. "Keeping Outsioders Out: Impurity at Qumran." In F. G. Martínez \& M. Popović (eds.) Defining Identities: We, You, and the Other in the Dead Sea Scrolls (s. 187-204). Leiden - Boston: Brill.

Heilke, T. W. 1990. Voegelin on the Idea of Race. An Analysis of Modern European Racism. Baton Rouge - London: Louisiana State University Press.

Herweg, R. M. 2004. "Menschenbild und Menschenwürde im Judentum angesichts der Herausforderung durch bioethische Fragen. Deutscher Katholikertag". Ulm: Pressezentrum, Dokument 2309.

Hogeterp, A. L. 2008. "Eschatological Identities In the Damascus Document." W: F. G. Martínez \& M. Popović (eds.) Defining Identities: We, You, and the Other in the Dead Sea Scrolls (s. 111-130). Leiden - Boston: Brill.

Homolka, W. 1999. "Bindung und Freiheit - Jüdisches Religionsgesetz heute“. W: M. Zemer (ed.) Jüdisches Religionsgesetz heute. Progressive Hallacha, mit der Einleitung von W. Homolka. Neukirchen-Vluyn: Neukirchener Verlag.

Jay, N. 1992. Throughout Your Generation Forever: Sacrifice, Religion, and Paternity. Chicago: Univ. of Chicago Press.

Jokiranta, J. 2008. "Social Identity Approach. Identity Constructing Elements in the Psalms Pesher." W: F. G. Martínez \& M. Popović (eds.) Defining Identities: We, You, and the Other in the Dead Sea Scrolls (s. 85-110). Leiden Boston: Brill.

Judd, R. 2007. Contested Rituals. Ithaca - London: Cornell University Press.

Landau, R. 2004. "Israel. Every Person Has Right to Have Children." W: E. Blyth \& R. Landau (eds.) Third Party Assisted Conception Across Cultures. Social, Legal, and Ethical Perspectives (s. 129-147). London - New York: Jessica Kingsley Publishers Ltd. 
von Linné, C. 1773. Vollständiges Natursystem, Erster Theil: Von den säugenden Thieren. Nürnberg.

Klawans, J. 2000. Impurity and Sin in Ancient Judaism. Oxford: Oxford University Press.

Kleingeld, P. 2007. "Kant's Second Thoughts on Race." The Philosophical Quarterly, Vol. 57, No. 229: 573-592.

Knust, J. Wright. 2011. Unprotected Texts: The Bible's Surprising Contradictions About Sex and Desire. New York: HarperCollins.

Lewis, J. J. 2009. Imaging Holiness. Toronto - Québec: McGill-Queen's University Press.

Levit, E. 1874. Die Circumcision der Israeliten beleuchtet vom ärztlichen und humanen Standpunkte von einem alten Arzte. Wien.

Lubarsky, S. B. 1984. "Judaism and the Justification of Abortion for Non-Medical Reasons." Journal of Reform Judaism, Vol. 31(4).

Mosse, George L. 2000. "The Jews: Myth and Counter-myth." W: L. Back \& J. Solomos (eds.) Theories of Race and Racism (s. 195-205). London - New York: Routledge.

Maimonides, M. 1904. The Guide for the Perplexed. Trans. from the original Arabic text by M. Friedländer: Jews College.

Mendes-Flohr, P. 1997. "Zarathustra's Apostle. Martin Buber and the Jewish Renaissance." W: J. Golomb (ed.) Nietzsche and Jewish Culture. London New York: Routledge.

Nowak, E. 2017. "Ciała w glorii. Z antropologicznego archiwum estetyzacji". Estetyka i Krytyka, Vol. 45(2): 103-118.

Nowak, E. 2014. "Doskonałość. Z genealogii human enhancement". Humaniora, Vol 1(5): 59-68. URL: www.humaniora.org

Peterson, D. 1982. Hebrews and Perfection. An Examination of the Concept of Perfection in the Epistle to the Hebrews. Cambridge UK: Cambridge University Press.

Popović, M. 2005. Reading the Human Body. Physiognomics and Astrology in the Dead Sea Scrolls and Hellenistic-Early Roman Period Judaism. Leiden: Brill.

Ramsden, E. 2008. "Eugenics from the New Deal to the Great Society: Genetics, Demography and Population Quality." Stud. Hist. Phil. Biol. \& Biomed. Sci. Vol. 39: 391-406.

Reershemius, G. 2009. "Gypsies and Orientalism in German Literature and Anthropology of the Long Nineteenth Century. Nicholas Saul. London: Legenda 2007." Romani Studies, Vol. 19(2): 185-186.

Rice, T. B. 1929. Racial Hygiene: A Practical Discussion of Eugenics and Race Culture. New York: The MacMillan Company.

Saleebi, C. W. 1909. Parenthood and Race Culture: An Outline of Eugenics. New York: Moffart, Yard, \& Co.

Scholem, G. 2007. Mistycyzm żydowski i jego główne kierunki. Tł. I. Kania. Warszawa: Aletheia.

Shildrick, M. \& R. Mykitiuk. 2006. Ethics of the Body: Postconventional Challenges. Cambridge, MA: MIT. 
Simon, J. 2000. "Ein Text wie Nietzsches Zarathustra". W: V. Gerhardt (Hg.), Also sprach Zarathustra (s. 225-256). Berlin: Akademie Verlag.

Spörri, M. 2013. Reines und gemischtes Blut. Bielefeld: Transcript ScienceStudies.

Starobinski, A. 1960. La biopolitique: Esai d'interprétation de l'histoire de l'humanité et des civilisations. Geneva: Imprimerie des Arts.

Sternberger, G. 2011. Einleitung in Talmud und Midrasch. München: C. H. Beck.

Todorov, Tzvetan. 2000. "Race and Racism". W: L. Back \& J. Solomos (eds.) Theories of Race and Racism (s. 64-70). London - New York: Routledge.

Torres Herring, Max S. 2006. Rassismus in der Vormoderne. Frankfurt/Main New York: Campus Verlag.

Voegelin, E. 1933a. Rasse und Staat. Tübingen: Mohr.

Voegelin, E. 1933b. Die Rassenidee in der Geistesgeschichte von Ray bis Carus. Tübingen: Junker und Dünnhaupt.

Washowsky, M. 2009. "Faith and Fertility in Reform Jewish Thought." W: E. Blyth \& R. Landau (eds.) Faith and Fertility. Attitudes towards Reproductive Practices in Different Religions from Ancient to Modern Times. Foreworded by R. Harries (s. 225-245). London - Philadelphia: Jessica Kingsley Publishers.

Weitzman, G. 2009. “'Give Me Children or Else I Am Dead': Orthodox Jewish Perspectives on Fertility." W: E. Blyth \& R. Landau (eds.) Faith and Fertility. Attitudes Towards Reproductive Practices in Different Religions from Ancient to Modern Times. Foreworded by R. Harries (s. 205-224). London - Philadelphia: Jessica Kingsley Publishers.

Weisinger, A. 2016. "Pre-Sinaitic Halkhic Observance As Interpreted By Medieval Authorities." URL:

https://www.academia.edu/20066648/Pre-Sinaitic_Halakhic_ Observance_As_Interpreted_By_Medieval_Authorities. Retrieved on 15.06.2016.

Zank, M. 2012. "The Heteronomy of Modern Jewish Philosophy." The Journal of Jewish Thought and Philosophy, Vol. 20(I): 99-134.

Žižek, S. 2004. "From Politics to Biopolitics... and Back." The South Atlantic Quarterly, Vol. 103: 2-3. Duke University Press. 


\title{
Ewa Nowak
}

(Adam Mickiewicz University in Poznań, ewanowak@amu.edu.pl)

Now Choose Life, So That You and Your Children May Live. Eschatology of Perfectibility, Niddah, and the Scandalon of Race Hygiene at 1850-1945.

\begin{abstract}
The formation and development of khalachic rules, in particular niddah, was always already oriented towards integral perfectibility of human life. The paper explores the integral life eschatology in Judaism and shows how Niddah has been manipulated by race hygienists and eugenicists 1850-1945 as a tool creating a myth of Jewish race on the one hand, and a counter-myth of the new superhuman race. That scandalous manipulation should be concidered when seeking analogies between the Jewish ideal of integral perfectibility and the Western eugenics.
\end{abstract}

Keywords: Niddah, ritual purity, health, perfectibility, messianic identity, bios, race, racism, eugenics, Nietzsche, Salebi, Rice.

Ethics in Progress (ISSN 2084-9257). Vol. 7 (2016). No. 1, Art. \#7, pp. 103-117.

doi: 10.14746/eip.2016.1.6 